\section{A blindagem midiática como dispositivo de enunciação ${ }^{1}$}

\author{
Ada Cristina Machado Silveira \\ Clarissa Schwartz \\ Carlos Renan Sanchotene
}

\section{Resumo:}

O texto dedica-se ao estudo de um termo posto em voga na cobertura jornalística brasileira em tempos recentes, o de blindagem propagada por via midiática. A noção surge no momento social, econômico e político do Brasil de efervescência de manifestações. A blindagem aqui tomada como dispositivo pode referir-se ao processo relativo ao contrato de comunicação ao deter propriedades de um dado suporte midiático, seu consequente produto e o conjunto de relações que seu reconhecimento pode engendrar. Ela caracterizaria uma dada estratégia editorial da mídia de referência que vem a ser denunciada por mídias alternativas e emergentes. A análise de ações envolvendo o uso do termo blindagem, seja na textualidade dos veículos jornalísticos (em suas versões on-line), seja na crítica propiciada pela mídia alternativa ou, ainda, nos comentários dos leitores (expressas em mídias sociais digitais), encaminha para a necessidade de aprofundamento do estudo no cenário da midiatização.

Palavras-chave: Blindagem Midiática. Midiatização. Dispositivo.

\section{Media shielding as an enunciation dispositive}

\begin{abstract}
:
This text is dedicated to the study of a term that has been much used recently in Brazilian journalistic coverage, shielding spread via media. The notion of media shield arises in a moment of social, economical and political protest effervescence. The shield as a dispositive would characterize a given editorial strategy of the reference media that is reported by alternative and emerging media. The shielding here taken as a device may refer to the process relating to the contract of communication in detaining properties of a given media, its consequent product and the set of relations that its recognition may engender. It would characterize a given editorial media strategy of reference that is being denounced by alternative and emerging media. The analysis of actions involving the use of the term shielding, whether in the textuality of journalistic vehicles (in its online versions), or in the criticism provided by the alternative media, or even in the comments of readers (expressed in digital social media), leads to need for further study in the mediatization scenario.
\end{abstract}

Keywords: Media shield. Mediatization. Dispositif.
Recebido em: 03.10.18

Aprovado em: 09.03.21

Ada Cristina

Machado Silveira

Professora da UFSM, membro do PPG Comunicação. Colaboradora do mestrado profissional em Comunicação e Indústria Criativa da Unipampa e pesquisadora do $\mathrm{CNPq}$, líder do Grupo de Pesquisa Comunicação, Identidades e Fronteiras.

E-mail:ada.silveira@ ufsm.br

\section{Clarissa Schwartz}

Foi professora colaboradora do departamento de Ciências da Comunicação, bolsista CAPES-PNPD Institucional do PPG Comunicação e membro do Grupo de Pesquisa Comunicação, Identidades e Fronteiras da UFSM.

E-mail: clarissaschwartz@ yahoo.com.br

Carlos Renan Sanchotene

Professor da Universidade Estadual de Minas Gerais. Foi bolsista DOCFIX CAPES-FAPERGS do PPG Comunicação junto ao Grupo de Pesquisa Comunicação, Identidades e Fronteiras da UFSM.

E-mail: carlos_sanchotene@yahoo.com.br

${ }^{1} \mathrm{O}$ artigo resulta de um percurso de investigação desenvolvido pelo grupo de pesquisa Comunicação, Identidades e Fronteiras (GruPesq CIFront), com financiamento do $\mathrm{CNPq}(\mathrm{PQ}$, Pibic, Pibic-AAf, Pibic-EM), FAPERGS (Probic e DOCFIX) e CAPES-PNPD.

Estudos em Jornalismo e Mídia v.18, n.1, jan./jun. 2021.

ISSNe 1984-6924 


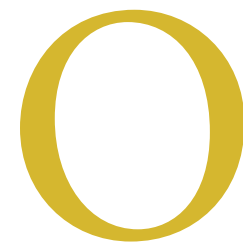

texto registra o estudo de um termo posto em voga na cobertura jornalística brasileira em tempos recentes, o de blindagem propagada por via midiática. A aproximação ao uso da noção de blindagem possibilitou a percepção de alguns padrões e sua possibilidade como categoria semiótica, buscando conceder consistência teórico-crítica a um termo consagrado no jargão profissional e que já alcançou as ruas. ${ }^{2}$

Entende-se que a noção de blindagem midiática surge no momento social, econômico e político do Brasil de efervescência de manifestações. $\mathrm{O}$ enriquecimento econômico favorecedor da ascensão de camadas populares provou um turbilhão de consumo de bens que acelerou a economia criativa e, especialmente, as atividades de disseminação de informações. Em tal contexto, a mídia de referência caracterizada pelo capital de controle nacional e organizada por oligopólios midiáticos desenvolveu um projeto editorial de forte oposição ao governo federal nos governos do Partido dos Trabalhadores (PT). Na arena de enfrentamento surgem questionamentos decorrentes de suas práticas, os quais adquirem visibilidade a partir da emergência das mídias sociais, da sanção do marco civil da internet e de projetos jornalísticos colaborativos que buscam constituir-se em alternativa em relação à abordagem da mídia tradicional (Peruzzo, 2008).

Acreditamos ser importante esclarecer que a emergência da noção de blindagem midiática é característica de uma polarização que cresceu progressivamente durante o período tomado a partir do ano de eleição para o primeiro mandato da presidente do Brasil, Dilma Rousseff, até sua deposição (2010-2016).

O uso da noção de blindagem midiática por parte da mídia alternativa, é representado especialmente por blogs, sites e portais, como recurso próprio do jargão jornalístico e que teria por finalidade a denúncia de uma prática considerada antinômica dos princípios deontológicos da profissão. Identifica-se que os verbos proteger, esconder, manipular, privilegiar, ocultar, favorecer e cobrir, também podem ser utilizados para denotar o mesmo significado. Etimologicamente, a palavra blindar deriva do alemão Blinde, que designa uma instalação oculta para proteger militares (ORIGEM, 2014). Com o desenvolvimento tecnológico, o termo expandiu-se para a área da segurança pública e privada (com os veículos e edificações à prova de armas de fogo) e foi incorporado pela imprensa. Observa-se ainda que além dos veículos jornalísticos, agentes sociais - notadamente pessoas públicas como políticos e até atletas - utilizam-se da blindagem como um recurso de gestão estratégica de imagem (SILVEIRA; HARTMANN; SCHWARTZ, 2020, p. 108). Nesse sentido, a blindagem como operação discursiva consiste num tour de force em favor de um sentido favorável ao que se quer escudar, buscando-se abrigá-lo numa ambiência privada daquelas violências que poderiam acarretar prejuízos e ônus a determinados agentes. No percurso de pesquisa desenvolvido, foi possível reconhecer basicamente três procedimentos de blindagem: a política; a pública; e a blindagem dita como propriamente midiática, objeto do presente relato.

$\mathrm{O}$ artigo está estruturado em três momentos. No primeiro, discute-se a prática da blindagem midiática tomada como dispositivo de enunciação. Na continuação, recorre-se ao estudo da midiatização como definidor de aspectos da blindagem midiática. Na sequência, a aplicação empírica se detém em três situações observadas em mídias sociais digitais e em veículos da mídia de referência com

${ }^{2}$ Uma versão anterior do artigo consta dos anais de evento onde foi comunicado, o I Seminário Internacional de Midiatização e Processos Sociais, da Unisinos, São Leopoldo, em 2017 vistas a analisar os impactos possíveis da midiatização frente à prática denunciada de blindagem midiática pelo jornalismo.

\section{A blindagem como dispositivo de enunciação}

A abordagem aqui referida toma a blindagem midiática enquanto dispositivo de enunciação. Reconhecendo a proposição de Michel Foucault (1979; 2000) 
para dispositivo, entende-se que ele o associa às relações de poder; o dispositivo teria competências de possibilitar um agrupamento de elementos heterogêneos que concorrem para a eficiência racional de um desempenho com vistas ao exercício do poder na sociedade. Analisando a questão do dispositivo em Foucault, Giorgio Agamben (2009) assim sistematiza:

a. É um conjunto heterogêneo, linguístico e não-linguístico, que inclui virtualmente qualquer coisa no mesmo título: discursos, instituições, edifícios, leis, medidas de polícia, proposições filosóficas etc. O dispositivo em si mesmo é a rede que se estabelece entre esses elementos. b. O dispositivo tem sempre uma função estratégica concreta e se inscreve sempre numa relação de poder. c. Como tal, resulta do cruzamento de relações de poder e de relações de saber. (AGAMBEN, 2009, p. 29).

A compreensão de dispositivo emerge de maneira semelhante à de rede que estabelece as relações de poder entre elementos heterogêneos, como podem sê-los os discursos, enunciados científicos, decisões regulamentares e outras que se estabelecem sobre o dito e o não-dito (Foucault, 1979, p. 244). Ele assume uma função que é estratégica e concede nexos articuladores de relações entre elementos distintos:

[...] trata-se no caso de uma certa manipulação das relações de força, de uma intervenção racional e organizada nestas relações de força, seja para desenvolvê-las em determinada direção, seja para bloqueá-las, para estabilizá-las, utilizá-las, etc... O dispositivo, portanto, está sempre inscrito em um jogo de poder, estando sempre, no entanto, ligado a uma ou a configurações de saber que dele nascem mas que igualmente o condicionam. $\mathrm{E}$ isto, o dispositivo: estratégias de relações de força sustentando tipos de saber e sendo sustentadas por eles. (Foucault, 1979, p. 246).

Jairo Ferreira destacaria dois aspectos na proposição do estudo dos dispositivos na Comunicação:

Um crítico, à redução do dispositivo a intermediário entre dois sujeitos. Outro positivo, de [...] compreender a produção do sentido não mais a partir do suporte, tecnologia ou linguagem, mas de um conjunto de relações práticas, discursivas e tecnológicas. (FERREIRA (2002a, p. 3).

Assim, blindagem tomada como dispositivo remete a um processo relativo ao contrato de comunicação ao deter propriedades de um dado suporte midiático, seu consequente produto e o conjunto de relações que sua recepção pode engendrar. A blindagem tomada como dispositivo enunciativo viria a caracterizar uma dada estratégia editorial da mídia de referência que vem a ser denunciada por mídias alternativas e emergentes, usualmente veiculadas por mídias sociais digitais. Opõem-se, em tal cenário, diferentes formações discursivas e ideológicas quando operadoras do exercício político do poder, consagrando-se, assim, o entendimento da noção de dispositivo como estratégia de ação em torno das relações de poder.

Importa recordar que Charaudeau $(2014$, p. 218) indica que o termo estratégia "vem da arte de conduzir as operações de um exército sobre um campo de ação" e sua expansão para várias disciplinas permite que seja compreendido como "toda ação realizada de maneira coordenada para atingir um certo objetivo". Essa perspectiva parece ir ao encontro de Greimas (1999, p. 122) quando registra que "a comunicação é um confronto de quereres e saberes; mais do que a enunciação de verdades e falsidades; ela é uma atividade que se submete ao princípio da eficácia”. E vale voltar à noção de dispositivo comunicacional em Maingueneau (2001):

Quando tratamos do mídium de um gênero de discurso, não basta levar em conta seu suporte material no sentido estrito (oral, escrito, manuscrito, televisivo etc)... é necessário partir de um dispositivo comunicacional que integre logo de saída o mídium. O modo de transporte e de recepção do enunciado condiciona a própria constituição do texto, modela o gênero de discurso. (Maingueneau, 2001, p. 72). 
Avançando em nossa proposição, aponta-se uma outra percepção da blindagem midiática como dispositivo que pode ser buscada nas próprias limitações que a convergência midiática produz e na resposta de grupos de mídia em seu cotidiano noticioso, principalmente quando de seu enfrentamento com as lógicas realizadas por mídias sociais. Trata-se de entender o momento presente como presidido por mudanças estruturais do Jornalismo, no qual os cânones da atividade encontram-se em profunda revisão (Deuze; Witschge, 2015).

Conforme Ferreira (2002a, p. 6) apontaria, o "deslocamento sobre os dispositivos permite pensá-los não mais como instrumentalização e alienação, mas como forma simbólica da frequentação, da experiência afetiva e corporal, em vista do jogo. Como técnica, refere-se a sua constituição na busca de eficácia, de otimização das condições de realização, e está, portanto, soldada ao conceito de estratégia". Em tais condições estritas, determinadas tecnicamente pela conjuntura da convergência digital e politicamente pela exacerbação do que já se chamou de différence (diferenças étnicas, religiosas e tantas outras...), os dispositivos necessitam profundos ajustes, dado que no caso do jornalismo, a atualização de seu "campo de significação" diversifica-se através de seus "temas, focos semânticos, modalidades discursivas e sentidos recorrentes”. Eles são:

[...] reproduzidos em várias ações sociais vinculadas aos discursos produzidos em dispositivos jornalísticos, ao mesmo tempo, em que, considerando essas trilhas reprodutivas, verifica-se as ressonâncias, bifurcações e conflitos de significação que emergem em lugares distintos da produção considerada em seu conjunto (Ferreira, 2002b, p. 2).

A diversidade das novas condições de circulação da mensagem jornalística na sociedade midiatizada aponta para a dificuldade de apreender o sentido e seus regimes de verdade. Tomar a noção de dispositivo como estratégia de ação em torno das relações de poder proporciona uma redefinição da atividade jornalística em novas bases, antecipando aquilo que vem sendo denominado de jornalismo de plataforma (VAN DIJCK; POELL; DE WALL, 2018). Ao organizar a interação entre os atualmente designados como usuários (e não mais leitores), sejam eles indivíduos, corporações ou instituições públicas, as plataformas facultam coletar e armazenar dados, ademais, de promover interações que afetam a formação da opinião pública.

${ }^{3}$ Tal aspecto refere-se a que o discurso tanto serve para positivar como para mascarar um silenciamento. Conforme aponta Foucault: "Sendo assim, tal discurso pode aparecer como programa de uma instituição ou, ao contrário, como elemento que permite justificar e mascarar uma prática que permanece muda; pode ainda funcionar como reinterpretação desta prática, dando-lhe acesso a um novo campo de racionalidade. Em suma, entre estes elementos, discursivos ou não, existe um tipo de jogo, ou seja, mudanças de posição, modificações de funções, que também podem ser muito diferentes". (FOUCAULT, 1979, p. 244).

\section{Midiatização e blindagem midiática}

A pesquisa que o presente texto sintetiza constou de dois momentos de análise da emergência da blindagem midiática tomada como categoria crítica para análise da cobertura jornalística brasileira. Um primeiro momento deteve-se na abordagem das condições de midiatização e seu impacto na sociedade e organizações de mídia do Brasil com vistas à cobertura de acontecimentos de caráter notadamente político. Entendemos que dele emerge um profundo questionamento comunicacional à atividade jornalística. Um segundo momento realizou análises empíricas da atividade jornalística que levam em conta a apropriação da noção de blindagem por distintos atores, contrastando o que antecipamos, grosso modo, como referente à atividade da mídia de referência contra a ação da mídia alternativa. ${ }^{3}$

Aborda-se a reflexão desenvolvida sobre a noção de midiatização recorrendo-se a distintos autores, como Antônio Fausto Neto (2008) a partir da proposição de Eliseo Verón (1997), e ainda a proposição de Stig Hjarvard (2012).

A discussão emerge do contexto de uma sociedade em processo de midiatização em que lógicas e protocolos midiáticos afetam campos sociais, sujeitos e ações (Verón, 1997). A intensificação da presença dos meios não apenas no âmbito do seu próprio campo, mas também pelo processo de deslocamento e de expansão para outros campos tem afetado o funcionamento discursivo e simbólico de diferentes práticas sociais. De acordo com Fausto Neto (2008), a constituição da sociedade, 
as formas de vida e interações têm sido transformadas em função da convergência tecnológica que foi disseminada na sociedade segundo lógicas de ofertas e de usos sociais dos meios.

Stig Hjarvard (2012) utiliza o termo "midiatização" para denotar a importância intensa e transformadora da mídia na cultura e na sociedade. Por midiatização, o autor se refere aos processos por meio dos quais cultura e sociedade tornam-se cada vez mais dependentes das mídias. Trata-se de um processo presidido por uma lógica que representaria "uma simplificação conceitual do modus operandi institucional, estético e tecnológico da mídia, incluindo-se aí as formas pelas quais a mídia distribui recursos materiais e simbólicos assim como opera com a ajuda de regras formais e informais" (Hjarvard, 2012, p. 54). Buscando compreender como a mídia passa a influenciar as diversas instituições sociais e domínios culturais, o autor combina dois níveis de análise: (1) a influência estruturante da mídia na interação social situada e (2) a institucionalização da mídia, tanto dentro de outras instituições como através do desenvolvimento da mídia como instituição semi-independente em si própria. A mídia, assim, coestrutura a comunicação e a interação (isto é, o nível da mediação), mas a midiatização ocorre através da institucionalização de padrões de interação particulares (regras formais e informais) e alocação dos recursos interacionais no interior de uma instituição social ou esfera cultural em particular. Assim, a mídia tem se tornado parte integrante da estruturação das interações e instituições sociais.

Segundo Fausto Neto (2008, p. 03), a sociedade na qual se desenvolve a midiatização "é constituída por uma nova natureza sócio-organizacional na medida em que passamos de estágios de linearidades para aqueles de descontinuidades, onde noções de comunicação, associadas às totalidades homogêneas, dão lugar às noções de fragmentos e às noções de heterogeneidades". A proposição do autor derruba os paradigmas que acreditavam na estruturação e homogeneização da sociedade frente à convergência tecnológica.

Uma perspectiva para a compreensão do conceito de midiatização é assumida por Verón (1997) ao considerar o fenômeno que transcende aos meios enquanto instrumentalidades, pois trata-se de um processo originado tanto pela evolução tecnológica quanto pelas demandas sociais. "Um meio de comunicação é um dispositivo tecnológico de produção-reprodução de mensagens associado a determinadas modalidades (ou práticas) de recepção de mensagens" (Verón, 1997, p. 13). Como um suporte técnico, esse dispositivo engendra processos complexos e simbólicos de produção e recepção, que configuram a estrutura do mercado discursivo.

Citando Igarza (2008), Valdettaro (2015, p. 187, tradução nossa) contextualiza que o desenvolvimento tecnológico das últimas décadas produziu um "fenômeno de convergência midiática na produção e divergência na recepção", esta última especialmente em função da evolução dos dispositivos. Resgatando Verón, a autora (2015, p. 189, tradução nossa) menciona que a coexistência dos meios de comunicação tradicionais e os novos meios de comunicação "define o caráter plenamente ubíquo da midiatização em nossas sociedades":

As modalidades para a construção do vínculo político a partir das chamadas "redes sociais" e o surgimento de novos grupos sociais - movimentos sociais de todo tipo sem nenhuma identidade formal - e os novos e disruptivos modos de exercício de protesto social (Valdettaro, 2013a), atravessam a disciplina forçando-a a construir novo conceitos sócio-antropológicos, no âmbito de uma hipermidiatização da política. (Valdettaro, 2015, p. 185) (tradução nossa). ${ }^{4}$

Assim, percebemos que Valdettaro (2015, p. 192) colocaria ênfase naquilo que no passado era reconhecido como "efeito" da mídia, vale dizer, manipular, persuadir, ocultar ou revelar, estupidificar, atuando no propósito de informar ou

${ }^{4}$ No original: "Las modalidades de construcción del vínculo político a partir de las llamadas "redes sociales", y la emergencia de nuevos colectivos - movimientos sociales de topo tipo sin una identidad formal -, $y$ de novedosos y disruptivos modos de ejercicio de la protesta social (Valdettaro, 2013a), atraviesan la disciplina forzándola a la construcción de nuevos conceptos socio-antropológicos en el marco de una hipermediatización de la política" (Valdettaro, 2015, p. 185). 
não informar. Num contexto de realidades midiáticas dissimiles ou antagônicas, como vivemos no cenário político brasileiro e de outras nações da atualidade, conjurando esforços midiáticos provenientes de diversas plataformas, veiculados ao vivo e em direto, ou editado, recorda Valdettaro (2015), busca-se incansavelmente sujeitar a razão e sustentar sua credibilidade midiática através de tecnologias diversas.

\section{A emergência da blindagem midiática e o jornalismo}

Retorna-se à preocupação central exposta no presente texto e apontada na dupla articulação da blindagem como dispositivo. Trata-se de compreender a blindagem em sua condição de enunciação manifesta nos discursos jornalísticos, a qual é capaz de reformular e reconfigurar os "modos de dizer" e o trabalho de produção de referência desta modalidade discursiva (Fausto Neto, 2008). Assim, a blindagem também decorreria de novas estratégias enunciativas possibilitadas pelo uso crescente de recursos tecnológicos convertidos em meios de interação que redefinem práticas sociais e processos de enunciação.

Apresentamos duas situações de observação e análise inicial de apropriação dos sentidos possíveis atribuídos à blindagem. Uma localizada na instância da produção e outra na instância da recepção. A construção de um corpus de pesquisa baseado em exemplos da imprensa brasileira permitiu identificar duas formas principais de prática da blindagem: a) ausência de abordagem de determinados assuntos na cobertura jornalística dos principais veículos de comunicação do Brasil e b) tratamento enunciativo diferenciado para situações semelhantes com intenção de deturpar, amenizar ou agravar a importância dos acontecimentos em tela. Através do acompanhamento de 46 sites, blogs e portais on-line, no período 2010-2015, encontramos 102 matérias em que foi possível identificar discursos com o uso e/ou a problematização do termo "blindagem" e de seus sinônimos. A partir da seleção e análise de um corpus de 16 matérias em que o termo "blindagem" foi utilizado nas manchetes das matérias, são reconhecíveis três usos principais: a) blindagem política: estratégia que objetiva proteger pessoas - especialmente políticos - ou instituições de investigações da justiça, sindicâncias públicas ou comissões parlamentares de inquérito; b) blindagem pública: tem por finalidade evitar o contato de pessoas públicas com a imprensa e a consequente exposição na mídia; c) blindagem midiática: tem propósito de excluir ou distorcer assuntos na cobertura jornalística alinhando interesses empresariais e políticos. Entre os três usos identificados, percebe-se uma maior recorrência da blindagem midiática, sendo que a tentativa de rompê-la é exercida principalmente pela própria mídia, através de atividades desenvolvidas pela mídia alternativa (SILVEIRA; HARTMANN; SCHWARTZ, 2020).

Em outro momento, a partir de um corpus composto por 53 matérias publicadas entre 2010 e 2015 em 26 portais, sites e blogs, nos concentramos em identificar os recursos de enunciação recorrentes nas denúncias de blindagem midiática. Observamos, no corpus selecionado, cinco recursos enunciativos destacados por Charaudeau (2013; 2014): polêmica; designação identificadora; dramatização; legitimação e engajamento. O primeiro recurso refere-se às matérias que buscam questionar o leitor; o segundo abarca reportagens que têm como objetivo apresentar provas, validar a denúncia apresentada de modo que o leitor não tenha dúvidas sobre seu conteúdo; a dramatização foi verificada através da comparação de coberturas jornalísticas de fatos semelhantes protagonizados por governo e oposição; o recurso da legitimação abarcou as reportagens que destacavam a credibilidade da fonte da denúncia de blindagem midiática; e, por último, o engajamento verificou-se como um recurso que buscou uma tomada de decisão (ou partido) por parte dos leitores (SILVEIRA; SCHWARTZ; HARTMANN, 2020). 
Entendemos que os recursos discursivos utilizados pela mídia alternativa para denunciar a blindagem midiática são uma tentativa de revelar as similitudes ocultadas pelas noções de semelhança reiteradas de forma coordenada pela mídia tradicional (Foucault, 2014). Enquanto a semelhança reconheceria o que está muito visível, a similitude se preocupa com o que está oculto, escondido, invisível: "A semelhança comporta uma única asserção, sempre a mesma: isto, aquilo, aquilo ainda, é tal coisa. A similitude multiplica as afirmações diferentes, que dançam juntas, apoiando-se e caindo umas em cima das outras" (Foucault, 2014, p. 61). A blindagem evidencia a tensão entre essas duas noções na prática jornalística.

Concebemos que blindagem midiática vem a ser uma resposta do Jornalismo à ambiguidade significacional e avança ao postular que o fenômeno se aponta enquanto estratégia de credibilidade e captação de notícias junto a sistemas que tradicionalmente organizam a realidade e mobilizam múltiplos agentes nas presentes condições de midiatização. A blindagem midiática aponta para um modelo narrativo que se impõe como estrutura de escritura jornalística com o propósito estratégico de intervir de forma a garantir antecipadamente como um determinado acontecimento será recebido. A operação semiótica da blindagem opera administrando a sequência de informações distribuídas, montando um encadeamento de informações selecionadas e recebida como um relato jornalístico de um fato objetivamente dado.

Acreditamos que se exercita assim a compreensão dos três lugares de pertinência correspondentes aos três lugares da máquina midiática. Tais lugares são compreendidos pela produção (lugar das condições de produção); produto terminado (lugar da construção textual) e recepção (lugar da interpretação ou reconhecimento). Tais lugares permitem propor um trajeto para a compreensão de sentido da blindagem. Nele, apresenta-se um esquema que vai desde um acontecimento bruto passando por um processo de transformação através do qual a instância midiática desenvolve estratégias para produzir notícias de eventos em favor de uma instância receptora, surgindo daí um evento interpretado. Trata-se de um contrato de comunicação (Charaudeau, 2009) concebido enquanto processo de transação. É através desse processo que a blindagem midiática se explicita como ação estratégica no contexto da ambivalência da linguagem. Como categoria semiótica, ela atua direcionando sentidos e esgotando ambiguidades.

Analisamos a seguir como ocorrem efetivamente as ressignificações feitas pela instância da recepção nos comentários em fanpages de mídias de referência (Isto É e Veja) e mídias alternativas (Brasil 247), ou seja, os efeitos produzidos a partir dos efeitos presumidos pela produção da blindagem no contexto das mídias sociais, em especial, no Facebook. Trata-se de uma abordagem exploratória realizada no ano de 2016 e que apresenta três situações em que ocorrem apropriações do termo blindagem por parte da instância receptora através de comentários a posts das revistas Isto É e Veja e ao blog alternativo Brasil 247.

\section{Situação 1}

No post do dia 20 de novembro de 2016, a Isto É publica uma entrevista com o ministro da Transparência, Torquato Jardim. Na entrevista, a revista questiona:

Isto É: O sr. acha que a Lava Jato está blindada? É exagero dizer que há pressões políticas? Torquato Jardim: O qualificativo é seu. Não posso interpretar o sentimento dos procuradores. É o sentimento deles. Pressão há em outras fontes que não o Poder Executivo. Eu acho que, sim, está blindada. Pelo menos do lado ao Executivo, a colaboração é irrestrita. Michel Temer já deixou isso claro" (VITÓRIA, 2016, grifo nosso).

A postagem teve 125 comentários e o uso do termo aparece de diversas formas: 
a) O povo como agente da blindagem:

Angela Fortes Fortes Brito Quem tá blindando a LAVA JATO é o povo. E esse mesmo povo tá de olho em vocês políticos.

Curtir $\cdot$ Responder $\cdot 21$ de novembro às 05:44

Terezinha Izabel Barcelos Pheula Está blindada por todo povo honesto deste saqueado país. Chega de ladrões governando e legislando!

Curtir $\cdot$ Responder $\cdot 21$ de novembro às 11:59

Elaine Baunilha A lava jato está blindada pelo povo brasileiro!!!

Curtir $\cdot$ Responder $\cdot 7 \cdot 20$ de novembro às $18: 18$

b) A blindagem como questionamento jurídico e social:

Franpes Santos E qual é a principal função da lei no Brasil, senão blindar o crime? Curtir $\cdot$ Responder $\cdot 20$ de novembro às 19:17

Sonia Nottoli Nunes Nao vejo a Lava Jato blindada, e sim grandes tentativas em extermina-la Curtir $\cdot$ Responder $\cdot 20$ de novembro às 22:59

Rômulo Pinheiro Landim A lava jato blindada? Mentira! Há duas tentativas de derrubar a lava jato, uma na câmara, através das 10 medidas contra corrupção, e a outra no senado, a lei de abuso do judiciário, liderado por Renan Calheiros.

Curtir $\cdot$ Responder $\cdot 20$ de novembro às 18:56

\section{c) A blindagem como ironia:}

Vitória Estrela Carro forte também é blindado e os bandidos mesmo assim atacam. Curtir $\cdot$ Responder $\cdot 20$ de novembro às $23: 40$

Edmilson Matos Tá blindado sim temer e psdb do chera po do aecio Curtir $\cdot$ Responder $\cdot 20$ de novembro às 18:04

\section{Situação 2}

No dia 10 de junho de 2016, Veja posta "Interpretação blinda Renan e outros investigados na Lava Jato". De acordo com a reportagem, Senado faz acordo e afirma que afastamento de aval do plenário:

Em meio à turbulência política provocada pelos pedidos de prisão da cúpula do PMDB por suspeitas de tentar travar a Operação Lava Jato e pelo pedido alternativo de afastamento do presidente do Senado, Renan Calheiros (PMDB-AL), uma manifestação da advocacia do Senado enviada nesta quinta-feira ao Supremo Tribunal Federal (STF) tenta dar ares de legitimidade a uma manobra orquestrada pelos partidos PP, PSC e SD para blindar parlamentares que correm o risco de ter seu mandato suspenso pela Justiça. (VEJA, 2016, grifo nosso). cações:

A publicação teve 136 comentários e a blindagem teve as seguintes ressignifi-

a) A blindagem como manobra política:

Loiva Bianchini Como assim blindagem? A poucos dias atrás, acompanhando a admissibilidade do impeachment, ouvi através da TV senado senadores (as) dizer que ninguém está acima da lei! Será que esse discurso valerá pra senador e o presidente da senado tbm? Ou é só pra presidente Dilma?

Curtir $\cdot$ Responder $\cdot 2 \cdot 10$ de junho às 19:10

Victor Finisguerra PT, PMDB, PSDB e PCdoB todos unidos para blindar esse bandido! Ninguém acha isso estranho??? Ninguém no senado federal quer ver esse vagabundo na 
cadeia?! Pq será? Será que é pq, se ele for preso e fechar delação premiada todos vão pra cadeia tb??? Isso é evidente!

Curtir $\cdot$ Responder $\cdot 3 \cdot 10$ de junho às 18:31

b) A blindagem como sentido associativo à criminalidade:

Gilvandro Lua Lua Bandidos procuram blindar bandidos!

Curtir $\cdot$ Responder $\cdot 11$ de junho às 18:56

Juliana Carone Os ladrões fazem leis para se protegerem! Nesse país é inviável a democracia porque os ladrões são blindados pela própria justiça!

Curtir $\cdot$ Responder $\cdot 11$ de junho às 01:44 $\cdot$ Editado

c) A blindagem em sentido associativo a personagens políticos:

Gil Granja Assim como blindam Lula?

Curtir $\cdot$ Responder $\cdot 11$ de junho às 09:20

\section{Situação 3}

No post do dia 07 de novembro de 2016, Brasil 247 publica coluna de Ribamar Fonseca intitulada "Mídia blinda Temer para mantê-lo no Planalto" sugere que as Organizações Globo blindam Temer em troca de verbas publicitárias:

O fato é que Temer, revelando-se muito habilidoso no trato com seus parceiros do golpe, tem mantido o apoio do Congresso na votação das matérias do seu interesse (...) Com isso, Temer conseguiu blindar-se, pois a grande imprensa, em especial a organização dos irmãos Marinho, ao mesmo tempo em que divulga um noticiário positivo sobre o seu governo, esconde as notícias negativas, motivo de críticas até da imprensa internacional. (...). Por essa e por outras é que a grande mídia brasileira deixou de ser referência para a imprensa estrangeira, que decidiu sediar repórteres da sua confiança no Brasil. (FONSECA, 2016, grifo nosso).

A publicação contou com 135 comentários e o uso do termo assim aparece:

a) A blindagem midiática associada à prática de propina:

Karla Mary Também! Vocês virão quanto o Temer destinou a sua divulgação pessoal na globo??? Milhões!!! Como a globo é mercenária, tudo nela só vai ao ar porque foi pago. Lá é assim: Pagou, Blindam.

Curtir $\cdot$ Responder $\cdot 11 \cdot 7$ de novembro às 11:40

Paulo Santos Sem dúvida ouve um acordaço chamado insençao de impostos perdão de dividas Globo. Record.Bandeirantes.RedTv. Aí esta Blindagem que mantém ele no poder. Mais esta casa vai cair.

Curtir $\cdot$ Responder $\cdot 2 \cdot 7$ de novembro às $17: 47$

Zeco Zeco Gonsa A mídia blinda temer porque recebeu do governo milhões que Dilma negou.

Curtir $\cdot$ Responder $\cdot 3 \cdot 7$ de novembro às $11: 43$

b) A blindagem midiática contra o denunciador:

Paulinho Silva Broa Deviam blindar é a cabeça do 247 para parar de sair besteiras de sua cabeça.

Curtir $\cdot$ Responder $\cdot 1 \cdot 7$ de novembro às $12: 16$

Cassia Franzoi Assim como vcs blindaram Dilma e LULA?

Curtir $\cdot$ Responder $\cdot 7$ de novembro às 12:57 
As três situações elencadas nos três veículos apontam usos que remetem a diferentes análises das centenas de comentários estudados. Conforme nossa análise destaca, na revista Isto É, os comentários evocam o povo como agente da blindagem, o uso do termo blindagem como questionamento jurídico e social e como ironia. Na segunda situação, os comentários à matéria da revista Veja mencionaram o termo blindagem para evocar manobra política, em sentido associativo à criminalidade e em sentido associativo a personagens políticos. Na terceira situação, os comentários ao blog Brasil 247 houve associação à prática de propina e a blindagem midiática é utilizada contra o denunciador. Trata-se de um conjunto de formações discursivas que requerem uma análise aprofundada, a qual nos dedicaremos oportunamente. Tais análises virão pontuadas pela perspectiva anunciada por Ferreira (2002a, p. 7) quando aponta que a significação é mais ampla e complexa do que o simbólico, dado que, para Foucault,

as relações entre saber e poder, a dispersão do poder em uma multiplicidade de dispositivos e a produção da individualidade pelas técnicas de exame e estatística (ver Tecnologias do Eu) estão associadas a uma profunda desconfiança em relação à técnica e à racionalidade que se expressa em seu conceito de dispositivo. (FERREIRA, 2002a, p. 7).

\section{E, principalmente que, há um equívoco ao resumir-se}

as possibilidades do dispositivo às intenções e estratégias daqueles que o construíram. Nesse sentido, a alternativa não é inventar dispositivos de resistência e de defesa, na medida em que a norma que o funda arma-se de poder, ou utiliza-se do saber como contrapoder, e como todo o saber e poder implicam em normalização, o resultado é sempre o avanço dessa. (Ferreira, 2002a, p. 7).

Ou seja, a marcha da blindagem ruma em direção a sua implementação cotidiana na produção noticiosa, buscando estabelecer vigorosamente uma forma de sentido que lhe forneça credibilidade, manejando entre formas simbólicas, funcionais, lógicas e minimamente referenciais de sentido.

\section{Considerações finais}

A crise do jornalismo na sociedade em processo de midiatização ultrapassa a questão jornalística e afeta os modos como se depositava valores em suas crenças sobre processos narrativos. Entendemos que a blindagem enquanto dispositivo de enunciação emerge como resposta a uma crise devida à dispersão do poder jornalístico frente à emergência das mídias sociais. A buscada eficiência racional reclama um desempenho com vistas ao exercício do poder que sempre foi reconhecido como inerente à atividade jornalística e constituinte de seu fazer e capital de ofício informativo.

O tratamento da blindagem midiática no ambiente amplo da midiatização social encara um tipo de resposta ao rearranjo de mensagens e significações no contexto da convergência digital. O marco político em que emerge o uso e denúncia da blindagem no Brasil na situação particular dos ataques ao governo Dilma Rousseff por parte da mídia de referência e sua denúncia por parte da crítica considerada mídia alternativa aponta para uma ampla dimensão de processos que, em presença de uns frente a outros, registram mudanças dramáticas para o jornalismo.

A breve análise das ações envolvendo o uso do termo blindagem, seja na textualidade dos veículos jornalísticos (em suas versões on-line), seja na crítica propiciada pela mídia alternativa ou, ainda, nos comentários dos leitores (expressas em mídias sociais digitais), encaminha para a necessidade de aprofundamento do estudo no cenário da midiatização, cenário emergente que aponta para alguns aspectos da complexidade de sua condição de dispositivo de enunciação. 
A (re)constituição identitária do jornalismo no momento em que a migração das versões on-line dos veículos para as denominadas plataformas, capazes de fazer convergir não só os conteúdos, mas também as práticas interativas entre jornalistas e usuários (leitores), usualmente denominadas colaborativas, apõem novas questões. A blindagem surge neste cenário profundamente midiatizado como uma sombra, um efeito malévolo e capaz de fazer reviver velhos dilemas políticos da atividade jornalística, não superados pela atualização tecnológica que vorazmente atacou a atividade noticiosa. A dimensão profundamente inovadora que a ambientação da atividade noticiosa nas novas plataformas aponta para fatores não-midiáticos na circulação da informação, como é o caso dos celebrados algoritmos, e como tais fatores relacionam-se com os valores consagrados pelo jornalismo profissional, atualmente em aparente conflito com as configurações midiáticas e/ou midiatizadas.

\section{Referências}

AGAMBEN, Giorgio. O que é o contemporâneo? e outros ensaios. Chapecó: Argos, 2009.

CHARAUDEAU, P. Identidade social e identidade discursiva, o fundamento da competência comunicacional. In: PIETROLUONGO, M. (Org.) O trabalho da tradução. Rio de Janeiro: Contra Capa, 2009.

CHARAUDEAU, P. Discurso das mídias. São Paulo: Contexto, 2013.

CHARAUDEAU, P. Estratégias de discurso. In: CHARAUDEAU. Patrick.; MAINGUENEAU, Dominique. Dicionário de análise do discurso. São Paulo: Contexto, 2014.

DEUZE, Mark; WITSCHGE, Tamara. Além do Jornalismo. Leituras do Jornalismo, Bauru, SP, v. 2, n. 2, 2015. Disponível em: https://www3.faac.unesp.br/leiturasdojornalismo/index.php/leiturasdojornalismo/article/view/74. Acesso em: 20 jan. de 2020.

FACEBOOK. Interpretação blinda Renan e outros investigados na Lava Jato. Disponível em: https://www.facebook.com/Veja/?fref=ts. Acesso em: 26 nov. 2016.

FACEBOOK. A Lava Jato está blindada. Disponível em: https://www.facebook. com/revistaISTOE/?fref=ts. Acesso em: 26 nov. 2016.

FACEBOOK. Mídia blinda Temer para mantê-lo no Planalto. Disponível em: https://www.facebook.com/Brasil247/?fref=ts. Acesso em: 26 nov. 2016.

FAUSTO NETO, Antônio. Fragmentos de uma analítica da midiatização. MATRIZes, São Paulo, Ano 1, n. 2, p. 53-91, abril de 2008.

FERREIRA, Jairo G. Mídia e conhecimento: objetos em torno do conceito de dispositivo. In: XXV Congresso Brasileiro de Ciências da Comunicação. Salvador, BA. Anais... São Paulo: Intercom, 2002.

FERREIRA, Jairo G. Dispositivos discursivos e o campo jornalístico. Ciberlegenda, Niteroi, v. 9, 2002b. Disponível em: https://periodicos.uff.br/ciberlegenda/article/view/36819/21394. Acesso em: 29 nov. 2016. 
FONSECA, R. Mídia blinda Temer para mantê-lo no Planalto. Site Brasil 247. Disponível em: http://www.brasil247.com/pt/colunistas/ribamarfonseca/264171/M\%C3\%ADdia-blinda-Temer-para-mant\%C3\%AA-lo-no-Planalto.htm. Acesso em: 26 nov. 2016.

FOUCAULT, Michel. Microfísica do poder. Rio de Janeiro: Graal, 1979.

FOUCAULT, Michel. Isto não é um cachimbo. São Paulo: Paz e Terra, 2014.

GREIMAS, Algirdas. A propósito do jogo. Tradução de Elizabeth Bastos Duarte. Verso e Reverso, São Leopoldo, n. 27, p. 119-124, 1999.

HJARVARD, Stig. Midiatização: teorizando a mídia como agente de mudança social e cultura. MATRIZes, São Paulo, Ano 5, n. 2, p. 53-91., jan./jun. de 2012.

MAINGUENEAU, Dominique. Análise de textos de comunicação. São Paulo: Cortez. 2001.

ORIGEM DA PALAVRA. SITE DE ETIMOLOGIA. Blindar. Disponível em: http:// origemdapalavra.com.br/site/palavras/blindar. Acesso em: 04 ago. 2014.

PERUZZO, Cicilia. Aproximações entre comunicação popular e comunitária e a imprensa alternativa no Brasil na era do ciberespaço. In: INTERCOM, 2008, Rio Grande do Norte. Anais... São Paulo: Intercom, 2008. Disponível em: http://www.intercom.org.br/papers/nacionais/2008/resumos/R3-0716-1.pdf. Acesso em: 06 set. 2014.

VITÓRIA, Giséle. Torquato Jardim - A Lava Jato está blindada. In: Revista Isto É - Entrevista. Disponível em: http://istoe.com.br/lava-jato-esta-blindada. Acesso em: 26 nov. 2016.

REVISTA VEJA. Em meio a acordão para salvar Renan, Senado afirma que afastamento precisa de aval do plenário. In: Política (Da Redação). Disponível em: http:// veja.abril.com.br/politica/em-meio-a-acordao-para-salvar-renan-senado-afirma-que-afastamento-precisa-de-aval-do-plenario. Acesso em: 26 nov. 2016.

SILVEIRA, Ada Cristina M. da; HARTMANN, Camila; SCHWARTZ, Clarissa. Polarização e blindagem midiática: o questionamento comunicacional da mediação jornalística. Index.comunicación, Madri, v. 10, n. 2, p. 83-114, 2020. Disponível em: https://journals.sfu.ca/indexcomunicacion/index.php/indexcomunicacion/ article/download/663/849/5679. Acesso em: 20 mai. 2020.

VALDETTARO, Sandra. Epistemología de la comunicación: una introducción crítica. Rosario: UNR, 2015.

VAN DIJCK, José; POELL, Thomas; DE WAAL, Martijn. The Platform Society: public values in a connective world. Nova York: Oxford University Press, 2018.

VERON, Eliseo. Esquema para el análisis de la mediatización. Revista Diálogos de la Comunicación, Lima-Peru, n. 48, 1997. Disponível em: https://comycult.files. wordpress.com/2014/04/veron_esquema_para_el_analisis_de_la_mediatizacion. pdf. Acesso em: 10 fev. de 2016. 